\title{
Measuring Interstitial Diffusion, Convection, and Binding Parameters in Mouse Tumors
}

\author{
Rakesh K. Jain, Lance L. Munn, and Dai Fukumura
}

Noninvasive techniques have been developed for the assessment of various parameters in normal and diseased tissues of mice. This protocol describes the measurement of extravascular parameters, including interstitial diffusion, convection, and binding parameters, in mouse tumors. A fluorescently labeled molecule of interest is infused into the tumor interstitium, followed by imaging using singlephoton microscopy or multiphoton laser-scanning microscopy (MPLSM). Fluorescence recovery after photobleaching (FRAP) with spatial Fourier analysis is performed. To measure interstitial diffusion coefficients, multiphoton FRAP is performed.

It is essential that you consult the appropriate Material Safety Data Sheets and your institution's Environmental Health and Safety Office for proper handling of equipment and hazardous materials used in this protocol.

Anesthetic: isofluorane $1 \%-3 \%$ inhalant (up to $5 \%$ for induction) or ketamine ( $80-100 \mathrm{mg} / \mathrm{kg}$ body weight $[\mathrm{BW}]) /$ xylazine $(5-10 \mathrm{mg} / \mathrm{kg} \mathrm{BW})$

Fluorescently labeled molecule of interest such as fluorescein isothiocyanate (FITC)-labeled antibody, viruses, or nanoparticles

Tetramethylrhodamine (TMR)-labeled dextran (MW $2 \times 10^{6} ; 2 \mathrm{mg} / \mathrm{mL}$ ) (for MPLSM only; see Step 1)

Equipment

Heating pad or similar device

Intravital microscopy workstation:

- Conventional single-photon microscope

The conventional single-photon microscopy system (Fig. 1A) consists of a microscope (upright or inverted) equipped with transillumination and fluorescence epi-illumination, a flashlamp excitation device, a set of fluorescence filters, a motor-controlled filter wheel, a charge-coupled device (CCD) camera, a video monitor, a video recorder, and a frame-grabber board for image digitization. Alternatively, a spinning-disk confocal miscroscope or a laser-scanning confocal microscope can be used. Advanced techniques require additional equipment such as a motorized $\mathrm{x}-\mathrm{y}$ stage with $\pm 1.0-\mu \mathrm{m}$ lateral resolution, an intensified CCD camera, a photomultiplier tube, and a dual-trace digital oscilloscope (Berk et al. 1997; Fukumura et al. 1997; Helmlinger et al. 1997; Jain et al. 2001, 2002).

Adapted from Live Cell Imaging, 2nd edition (ed. Goldman et al.). CSHL Press, Cold Spring Harbor, NY, USA, 2010.

(C) 2013 Cold Spring Harbor Laboratory Press

Cite this article as Cold Spring Harb Protoc; 2013; doi:10.1101/pdb.prot075721 
A Conventional epifluorescence intravital microscopy

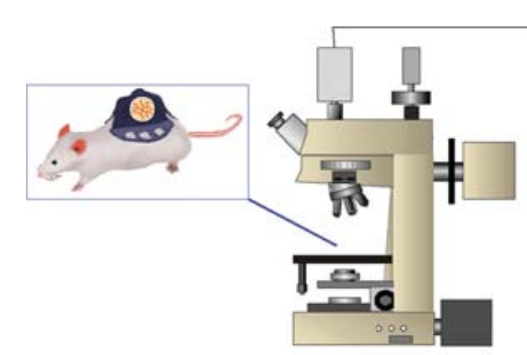

Upright microscope

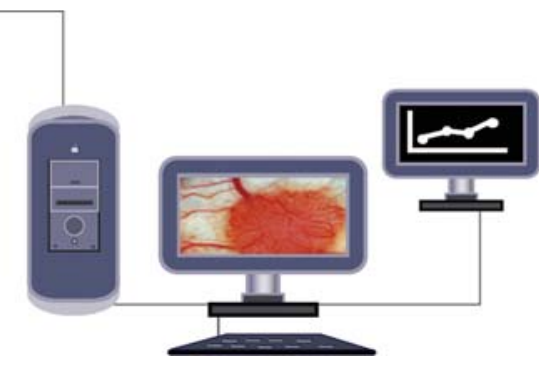

Digital image acquisition and analysis station

B Laser-scanning multiphoton intravital microscopy

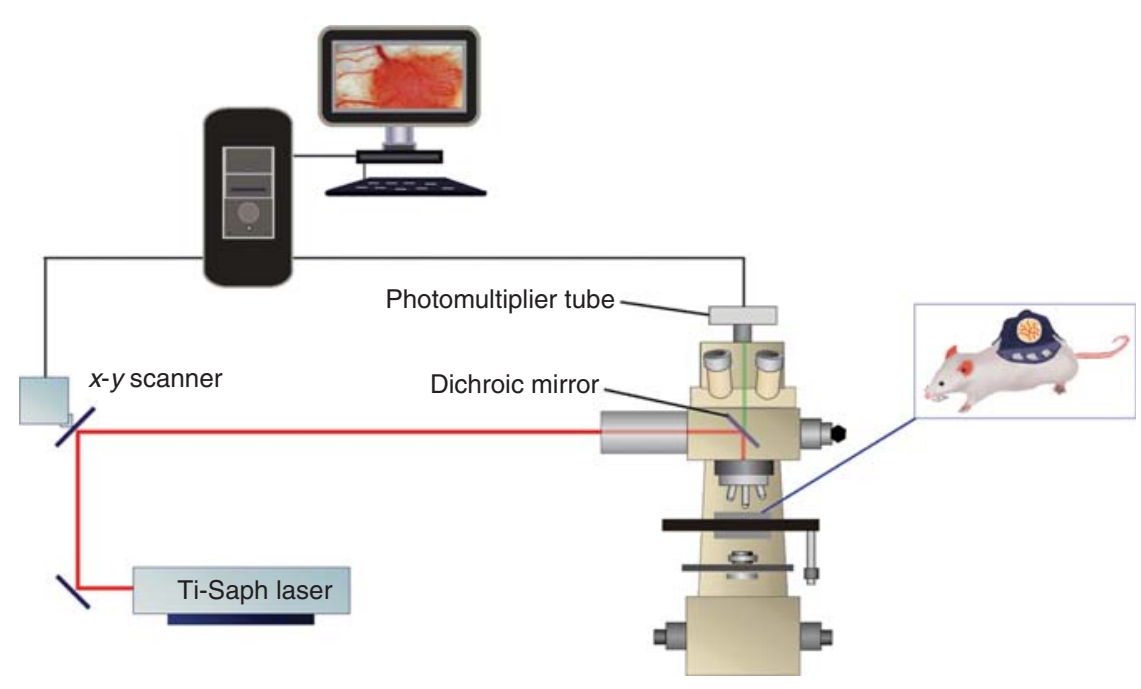

FIGURE 1. Intravital microscopy workstations. Mouse tumor models are observed using $(A)$ conventional intravital microscopy or $(B)$ MPLSM. With appropriate tracer molecules and/or engineered vectors/cells and computer-assisted image analysis, one can monitor tumor size, vessel density, vessel diameter, RBC velocity, leukocyte endothelial interaction, vascular permeability, tissue $\mathrm{pO}_{2}, \mathrm{pH}$, gene promoter activity, enzyme activity, and delivery of drugs, including genes. (B: Adapted, with permission, from Brown et al. 2001.)

\section{- Multiphoton laser-scanning microscope (MPLSM)}

The MPLSM system (Fig. 1B) consists of a mode-locked Ti:sapphire laser and an x-y laser scanner purchased either as part of a multiphoton system or as a confocal system with further modifications for good infrared transmission. The laser beam first passes through a Pockels cell, which allows rapid ( $1-\mu \mathrm{sec})$ modulation of laser intensity and then is directed by the scan head into the side-entry or top-entry port of an upright epifluorescence microscope. Nondescanned photomultiplier tubes are used for imaging through significant depths of scattering tissue and should be introduced into the beam path via a dichroic beam splitter located in the beam path between the scan head and the objective lens (Denk et al. 1990; Brown et al. 2001). The system also requires a CCD camera, and a digital image and analysis station.

\section{METHOD}

Perform imaging procedures with the animal under appropriate anesthesia and with full approval by the Institutional Animal Care and Use Committee. During the procedure, maintain the animal's core body temperature at $36^{\circ} \mathrm{C}-37^{\circ} \mathrm{C}$ using a heating pad or similar device.

1. Infuse a fluorescently labeled molecule into the tumor interstitium either via extravasation after intravenous injection or local low-pressure microinfusion (Netti et al. 2000; Pluen et al. 2001; 
R.K. Jain et al.

Ramanujan et al. 2002). For MPLSM, highlight the vessels by injecting $100 \mu \mathrm{L}$ of TMR-labeled dextran (MW $\left.2 \times 10^{6}, 10 \mathrm{mg} / \mathrm{mL}\right)$ into the tail vein.

For single-photon microscopy procedures, proceed to Step 2. For MPLSM, proceed to Step 5.

\section{Single-Photon Microscopy Procedures}

2. Bleach a subpopulation of the fluorescent molecules using a brief (approximately a millisecond) flash of focused laser light. During the bleaching flash, shutter the camera to avoid damage to the electronics.

3. Generate consecutive images of the bleached region via epifluorescence, and capture them on the CCD camera as unbleached fluorophore diffuses back into the bleached region.

4. Perform spatial Fourier analysis of the fluorescence recovery images as described previously (Chary and Jain 1989; Berk et al. 1993, 1997) to extract diffusion coefficients, convection velocity, and binding parameters.

\section{MPLSM Procedures}

5. Generate fluorescence with 840-nm excitation and collect it with 535DF40 (FITC) and 610DF75 (TMR) emission filters and a 570LP dichroic mirror.

6. Identify a location of interest from MPLSM images of blood vessels. Park the multiphoton focal volume at the location using the LSM control software. Bleach out a subpopulation of the fluorescent molecules using a brief (approximately a submillisecond) flash of high-intensity laser light.

7. Monitor the bleached region with the same laser beam but greatly attenuated. Use a multichannel scaler to record the recovery in fluorescence of the bleached region as unbleached fluorophores diffuse back into the bleached region.

8. Perform a mathematical analysis of the fluorescence recovery curve to extract the diffusion coefficient of the labeled molecules (Brown et al. 1999).

\section{ACKNOWLEDGMENTS}

The work described here was supported by grants from the National Institutes of Health, the National Science Foundation, the American Cancer Society, the United States Army, the National Foundation for Cancer Research, and the Whitaker Foundation.

\section{REFERENCES}

Berk DA, Yuan F, Leunig M, Jain RK. 1993. Fluorescence photobleaching with spatial Fourier analysis: Measurement of diffusion in light-scattering media. Biophys J 65: 2428-2436.

Berk DA, Yuan F, Leunig M, Jain RK. 1997. Direct in vivo measurement of targeted binding in a human tumor xenograft. Proc Natl Acad Sci 94: 1785-1790.

Brown EB, Wu ES, Zipfel W, Webb WW. 1999. Measurement of molecular diffusion in solution by multiphoton fluorescence photobleaching recovery. Biophys J 77: 2837-2849.

Brown EB, Campbell RB, Tsuzuki Y, Xu L, Carmeliet P, Fukumura D, Jain RK. 2001. In vivo measurement of gene expression, angiogenesis, and physiological function in tumors using multiphoton laser scanning microscopy. Nat Med 7: 864-868.

Chary SR, Jain RK. 1989. Direct measurement of interstitial convection and diffusion of albumin in normal and neoplastic tissues by fluorescence photobleaching. Proc Natl Acad Sci 86: 5385-5389.

Denk W, Strickler JH, Webb WW. 1990. Two-photon laser scanning fluorescence microscopy. Science 248: 73-76.

Fukumura D, Yuan F, Endo M, Jain RK. 1997. Role of nitric oxide in tumor microcirculation: Blood flow, vascular permeability, and leukocyte-endothelial interactions. Am J Pathol 150: 713-725.
Helmlinger G, Yuan F, Dellian M, Jain RK. 1997. Interstitial pH and $\mathrm{pO}_{2}$ gradients in solid tumors in vivo: High-resolution measurements reveal a lack of correlation. Nat Med 3: 177-182.

Jain RK, Munn LL, Fukumura D. 2001. Transparent window models and intravital microscopy. In Tumor models in cancer research (ed. Teicher BA), pp. 647-671. Humana, Totowa, NJ.

Jain RK, Munn LL, Fukumura D. 2002. Dissecting tumor pathophysiology using intravital microscopy. Nat Rev Cancer 2: 266-276.

Netti PA, Berk DA, Swartz MA, Grodzinsky AJ, Jain RK. 2000. Role of extracellular matrix assembly in interstitial transport in solid tumors. Cancer Res 60: 2497-2503.

Pluen A, Boucher Y, Ramanujan S, McKee TD, Gohongi T, di Tomaso E, Brown EB, Izumi Y, Campbell RB, Berk DA, et al. 2001. Role of tumorhost interactions in interstitial diffusion of macromolecules: Cranial vs. subcutaneous tumors. Proc Natl Acad Sci 98: 4628-4633.

Ramanujan S, Pluen A, McKee TD, Brown EB, Boucher Y, Jain RK. 2002. Diffusion and convection in collagen gels: Implications for transport in the tumor interstitium. Biophys J 83: 1650-1660. 


\section{Measuring Interstitial Diffusion, Convection, and Binding Parameters in Mouse Tumors}

Rakesh K. Jain, Lance L. Munn and Dai Fukumura

Cold Spring Harb Protoc; doi: 10.1101/pdb.prot075721

\begin{tabular}{cc}
$\begin{array}{r}\text { Email Alerting } \\
\text { Service }\end{array}$ & Receive free email alerts when new articles cite this article - click here. \\
\hline $\begin{array}{c}\text { Subject } \\
\text { Categories }\end{array}$ & $\begin{array}{c}\text { Browse articles on similar topics from Cold Spring Harbor Protocols. } \\
\text { In Vivo Imaging (334 articles) } \\
\text { In Vivo Imaging, general (168 articles) } \\
\text { Mouse (437 articles) }\end{array}$ \\
& \\
\hline
\end{tabular}

